\title{
Frontal White Matter Hyperintensity Is Associated with Verbal Aggressiveness in Elderly Women with Alzheimer Disease and Amnestic Mild Cognitive Impairment
}

\author{
Noriko Ogama ${ }^{a-c}$ Takashi Sakurai ${ }^{a}$ Naoki Saji ${ }^{a}$ Toshiharu Nakai ${ }^{d}$ \\ Shumpei Niida ${ }^{e}$ Kenji Toba ${ }^{a}$ Hiroyuki Umegakic Masafumi Kuzuyac, ${ }^{c}$ \\ ${ }^{a}$ Center for Comprehensive Care and Research on Memory Disorders, National Center \\ for Geriatrics and Gerontology, Obu, Japan; ${ }^{b}$ Department of Geriatric Medicine, National \\ Center for Geriatrics and Gerontology, Obu, Japan; ' Department of Community Healthcare \\ and Geriatrics, Nagoya University Graduate School of Medicine, Nagoya, Japan; \\ dNeurolmaging and Informatics, National Center for Geriatrics and Gerontology, \\ Obu, Japan; ${ }^{e}$ Medical Genome Center, National Center for Geriatrics and Gerontology, \\ Obu, Japan; ${ }^{f}$ Institutes of Innovation for Future Society, Nagoya University, Nagoya, Japan
}

Keywords

Aggression - Alzheimer disease - Mild cognitive impairment - Behavioral and psychological symptoms in dementia - White matter hyperintensities

\begin{abstract}
Background/Aims: Behavioral and psychological symptoms of dementia (BPSD) are exhibited in most patients with Alzheimer disease (AD). Although white matter hyperintensity $(W M H)$ is often observed with $A D$, the precise role of WMH in BPSD remains unclear. The current study aimed to identify the impact of regional WMH on specific features of BPSD in persons with mild to moderate $A D$ and amnestic mild cognitive impairment $(\mathrm{aMCl})$. Methods: $A$ sample of 256 female outpatients with $\mathrm{AD}(n=217)$ and $\mathrm{aMCl}(n=39)$ were recruited. We assessed BPSD using the Dementia Behavior Disturbance Scale. WMH and brain atrophy were evaluated using an automatic segmentation program. Regional WMH was evaluated as periventricular hyperintensity (PVH) and deep $\mathrm{WMH}$ in frontal, temporal, occipital, and parietal lobes. Results: Whole-brain WMH was associated with verbal aggressiveness. In multivariate analysis, $\mathrm{PVH}$ in the frontal lobe was independently associated with verbal aggressiveness after adjustment for brain atrophy and clinical confounders. Conclusion: The current results indicated that PVH in the frontal lobe was independently associated with verbal aggressiveness.


Ogama et al.: Frontal White Matter Hyperintensity Is Associated with Verbal Aggressiveness in Elderly Women with $\mathrm{AD}$ and $\mathrm{aMCl}$

\section{Introduction}

Behavioral and psychological symptoms of dementia (BPSD) are used to describe a heterogeneous group of noncognitive symptoms, defined as signs and symptoms of disturbed perception, thought content, mood, or behavior [1]. BPSD are observed in nearly all persons with dementia during the course of illness [2]. Furthermore, BPSD are exhibited in approximately half of patients with mild cognitive impairment (MCI) [3]. BPSD are associated with poor outcomes, including reduced quality of life [4], increased caregiver burden [5], conversion from MCI to dementia [6], and progression to severe dementia and/or death [7]. Therefore, identifying the factors associated with BPSD and developing preventive strategies could be valuable in persons with MCI and the early stages of dementia.

White matter hyperintensity (WMH) is presumed to be of vascular origin and is commonly used as a marker of cerebrovascular disease. WMH is considered to coexist with Alzheimer disease (AD) pathologies [8], patients with AD have been found to exhibit a greater WMH volume, and amnestic MCI (aMCI) patients exhibit an intermediate level of WMH between that of AD patients and healthy controls with normal cognition [9]. Confluent and extensive WMH is associated with not only cognitive impairment, but also mobility dysfunction and functional decline [8-13]. Several previous imaging studies have examined the association between WMH and BPSD [10, 14-18]. However, these studies have reported inconsistent results. While one study found that patients with WMH were more likely to exhibit BPSD [17], another study did not find any association [15]. Several studies have examined the association between WMH and specific patterns of BPSD, but their results are also inconsistent $[10,14-16]$. These inconsistencies may be explained by differences in WMH rating scales. Importantly, the regional impact of WMH on specific patterns of BPSD has not been considered. In addition, expression and BPSD features vary according to the clinical course of dementia [2], and many factors, including gender, cognitive impairment, medical health, medication, and environmental factors, are also known to influence the occurrence of BPSD $[19,20]$.

Considering these issues, the current study sought to clarify the relationship between a volumetric assessment of WMH and BPSD in early AD and aMCI. We hypothesized that regional WMH would be independently associated with specific features of BPSD. Thus, the aim of this study was to determine the regional effects of WMH on specific features of BPSD after adjusting for brain atrophy and clinical confounders.

\section{Methods}

\section{Participants}

This study obtained ethical approval from the National Center for Geriatrics and Gerontology (NCGG). All candidate patients and their caregivers provided written informed consent before participating in the study. We enrolled 256 outpatients who visited the NCGG hospital between 2010 and 2013 with a diagnosis of probable or possible AD $(n=217)$ or aMCI $(n=$ 39 ) based on the criteria of the National Institute on Aging/Alzheimer's Association Workgroup [21, 22]. Because the prevalence of BPSD is dependent on gender [19], this study included only female patients. All subjects were aged 65-85 years and had Mini-Mental State Examination (MMSE) scores $\geq 15$ and Barthel Index scores $\geq 80$. Patients with delirium, a history of stroke or cortical lesions detected on magnetic resonance (MR) images, severe conditions, such as cardiac failure, renal disorder, or liver dysfunction, or neurological disorders other than AD were excluded from the study. 


\section{Assessment of BPSD and Clinical Confounding Factors}

We used clinical data collection in the NCGG Medical Genome Center Biobank, which stores bioresources and clinical data for biomedical research. BPSD was evaluated using the Dementia Behavior Disturbance Scale (DBD) [23]. Patients' caregivers were surveyed and rated the occurrence of particular behaviors on a scale from 0 to 4 points $(0$, never; 1 , rarely; 2 , sometimes; 3 , often; 4 , all the time). In our previous study of a large cohort of patients with AD, factor analysis was carried out on 28 sub-items of the DBD; the DBD was classified into 6 domains [5]. The domain "incontinence," included in the scale, identifies the relevance of regional WMH [24]. Therefore, the current study examined the following 5 domains: behavioral disturbance (e.g., wandering, getting lost outside), verbal aggressiveness (e.g., accusations, verbal abusiveness), motor aggressiveness (e.g., physical attacks, destroys property or clothing), memory impairment (e.g., asking the same question repeatedly, losing, misplacing, or hiding things), and apathy (e.g., lack of interest in daily activities, sleeping excessively during the day).

Global cognition was assessed with the MMSE [25]. Basic/instrumental activities of daily living were assessed with the Barthel Index and Lawton Index, respectively [26, 27]. Depressive mood was evaluated with the self-rated Geriatric Depression Scale-15 (GDS) and Vitality Index, respectively $[28,29]$. Geriatric syndrome was evaluated with the following items: lower urinary tract symptoms (urinary incontinence, urinary difficulty, and urinary frequency), pain (lumbago, back pain, leg and upper limb pain), fatigue, constipation/diarrhea, and sleep problems. We assessed polypharmacy and the following medications: use of donepezil, memantine hydrochloride, antipsychotics, and anti-anxiety/sleeping medicines. Polypharmacy was defined as taking 5 or more types of oral medicine [30]. The patients' lifestyle factors and social conditions were assessed using the following questions: participation in social activity (yes or no), exercise (none, once or more per week), need for financial support (yes or no), alcohol consumption (daily or none), current smoking status (yes or no), and living situation (with parents or children, spouse, alone or other). In cases where patients lived alone, we obtained DBD information from the patient's family, who provided as much information as they could about the patient's behaviors. If the patient's family could not answer all questions about the patient's behavior, the case was excluded from the study.

\section{Evaluation of WMH and Brain Atrophy}

Image acquisition parameters of MR imaging and methodological details were the same as those described in our previous study [24]. Briefly, all participants underwent 1.5-T brain MR imaging (Siemens Avanto, Germany; or Philips Ingenia, The Netherlands) with T1-weighted, T2-weighted, and fluid-attenuated inversion recovery sequence. WMH and brain atrophy were quantified using an automatic segmentation application (SNIPER, Software for Neuro-Image Processing in Experimental Research, Department of Radiology, Leiden University Medical Center, The Netherlands) [31]. Brain tissue was classified as frontal, temporal, occipital, and parietal lobes, and WMH was separated into periventricular hyperintensity (PVH) and deep WMH (DWMH). Because automatic segmentation of WMH mostly recognized DWMH in continuity with $\mathrm{PVH}$, the distinction was manually classified [32]. Global brain atrophy was assessed by parenchyma, which is the subtraction of cerebrospinal fluid from intracranial (IC) volume, corresponding to the sum of total gray and white matter volumes. To minimize the bias of individual brain size, total and regional WMH and parenchyma were divided by the IC volume.

\section{Statistical Analysis}

All data were analyzed using the Japanese version of SPSS for Windows version 22.0 (IBM Corporation, Armonk, NY, USA). First, we performed multiple regression analyses to 
identify the association between MR imaging parameters and DBD subcategories. Second, to explore potential risk factors for BPSD, we performed single regression analysis. We calculated the coefficient of determination for each clinical index to determine the association with DBD subcategories. Finally, to identify the independent risk factors for BPSD, we conducted 2 sets of multiple regression analyses. Dependent variables were DBD subcategories and sub-items. Age, education, regional WMH, brain atrophy, and classical confounders known to influence development of BPSD (i.e., global cognitive function, geriatric syndrome, medication, and social activity [20]) were entered as independent variables in model 1. Age, education, regional WMH, brain atrophy, classical confounders, and clinical indices showing an association with DBD subcategories were entered as independent variables in model 2. Variance inflation factors were calculated for all multiple regression models and indicated no violation of linearity and multicollinearity. The level of statistical significance was set at $p<0.05$.

\section{Results}

\section{Clinical Data}

The clinical profiles of the study participants are shown in Table 1 . The mean age was $77.3 \pm 5.2$ years, and the total MMSE score was $21.2 \pm 3.7$. The total DBD score was $15.5 \pm 10.6$. In MR imaging analysis, mean IC volume and total WMH were $1,328.6 \pm 98.3 \mathrm{~mL}$ and $17.0 \pm$ $17.7 \mathrm{~mL}$, respectively. Regional distribution of WMH exhibited a high prevalence in the frontal $(9.5 \pm 9.6 \mathrm{~mL})$ and parietal lobes $(5.8 \pm 7.0 \mathrm{~mL})$ compared to other regions. Because automatic segmentation recognizes WMH as 3-D continuity in each MR imaging slice [32], most WMH was recognized as PVH $(16.0 \pm 17.3 \mathrm{~mL})$, and there was markedly less DWMH $(1.0 \pm 1.3 \mathrm{~mL})$.

\section{Associations between MR Imaging Parameters and BPSD Subdomains}

The associations between WMH and brain atrophy with DBD subcategories are shown in Table 2. After adjustment for age and education, total WMH was associated with verbal aggressiveness. In the regional analysis, PVH in the frontal lobe was associated with verbal aggressiveness. However, other regional PVH and DWMH were not associated with DBD subcategories. Brain atrophy was not associated with any DBD subcategories.

\section{Association between Clinical Parameters and Verbal Aggressiveness}

To explore the clinical confounders for verbal aggressiveness, we performed single regression analysis and calculated coefficients of determination (Table 3). The results revealed that verbal aggressiveness was significantly associated with fewer years of education, lower MMSE scores, decline of basic/instrumental activities of daily living, low vitality, number of geriatric syndromes, and fatigue. Regarding medications, verbal aggressiveness was significantly associated with treatment with antipsychotics, but other medications, including the dosage of donepezil, were not associated with verbal aggressiveness. None of the indices of lifestyle and social conditions, such as living situation, were associated with verbal aggressiveness.

\section{Independent Risk Factors for Verbal Aggressiveness}

Finally, to explore independent risk factors for verbal aggressiveness, we conducted 2 sets of multiple regression analyses (Table 4). The domain of verbal aggressiveness included the following 4 sub-items: "makes unwarranted accusations," "verbally abusive, swears," "cries or laughs inappropriately," and "screams for no reason" [5]. Therefore, we examined the relationship between regional WMH and verbal aggressiveness including these sub-items. 
Table 1. Clinical characteristics of study participants $(n=256)$

\begin{tabular}{|c|c|c|}
\hline Age, years & $77.3 \pm 5.2$ & \\
\hline Education, years & $10.1 \pm 2.0$ & \\
\hline Mini-Mental State Examination & $21.1 \pm 3.7$ & \\
\hline Barthel Index & $98.5 \pm 3.8$ & \\
\hline Lawton Index & $6.1 \pm 1.7$ & \\
\hline Geriatric Depression Scale & $4.3 \pm 2.6$ & \\
\hline Vitality Index & $9.1 \pm 1.1$ & \\
\hline Dementia Behavior Disturbance Scale & $15.5 \pm 10.6$ & \\
\hline \multicolumn{3}{|l|}{ Geriatric syndromes } \\
\hline Number of geriatric syndromes & $1.6 \pm 1.3$ & \\
\hline Lower urinary tract symptoms & $85(33.2)$ & \\
\hline Pain & $146(57.0)$ & \\
\hline Fatigue & $69(27.0)$ & \\
\hline Constipation or diarrhea & $61(23.8)$ & \\
\hline Sleep problems & $44(17.2)$ & \\
\hline \multicolumn{3}{|l|}{ Medication } \\
\hline Polypharmacy & $119(46.5)$ & \\
\hline Donepezil & $55(21.5)$ & \\
\hline Memantine hydrochloride & $2(0.8)$ & \\
\hline Antipsychotics & $26(10.2)$ & \\
\hline Anti-anxiety/sleeping medicine & $66(25.8)$ & \\
\hline \multicolumn{3}{|l|}{ Lifestyle } \\
\hline Social activity & $83(32.4)$ & \\
\hline Exercise, once or more/week & $174(68.0)$ & \\
\hline Finance, support needed & $19(7.4)$ & \\
\hline Alcohol, daily drinking & $19(7.4)$ & \\
\hline Current smoking & $6(2.3)$ & \\
\hline \multicolumn{3}{|l|}{ Social condition } \\
\hline Living with parents or children & $122(47.7)$ & \\
\hline Living with spouse & $85(33.2)$ & \\
\hline Living alone or other & $49(19.1)$ & \\
\hline \multicolumn{3}{|l|}{ MR imaging analysis } \\
\hline IC volume, $\mathrm{mL}$ & $1,328.6 \pm 98.3$ & \\
\hline PAR, mL & $998.2 \pm 82.0$ & $75.1 \%^{\mathrm{a}}$ \\
\hline WMH total, mL & $17.0 \pm 17.7$ & $1.28 \%^{\mathrm{a}}$ \\
\hline Frontal lobe, mL & $9.5 \pm 9.6$ & $0.72 \%^{\mathrm{a}}$ \\
\hline Temporal lobe, mL & $1.2 \pm 1.6$ & $0.09 \%^{\mathrm{a}}$ \\
\hline Occipital lobe, $\mathrm{mL}$ & $0.5 \pm 0.7$ & $0.04 \%^{\mathrm{a}}$ \\
\hline Parietal lobe, $\mathrm{mL}$ & $5.8 \pm 7.0$ & $0.44 \%^{\mathrm{a}}$ \\
\hline Periventricular area, mL & $16.0 \pm 17.3$ & $1.20 \%^{\mathrm{a}}$ \\
\hline Deep subcortical areas, mL & $1.0 \pm 1.3$ & $0.08 \%^{\mathrm{a}}$ \\
\hline
\end{tabular}

Data are presented as means \pm standard deviations or $n(\%)$ unless otherwise indicated. IC, intracranial; $\mathrm{MR}$, magnetic resonance; PAR, parenchyma; WMH, white matter hyperintensity. ${ }^{\text {a } \%}$ of IC volume.

In model 1, age, education, PVH in the frontal lobe, brain atrophy, and classical confounders were entered as independent variables. The results revealed that PVH in the frontal lobe was independently associated with the category of verbal aggressiveness and the sub-items "makes unwarranted accusations" and "verbally abusive, swears." However, PVH in the frontal lobe was not associated with "cries or laughs inappropriately" or "screams for no reason" ( $\beta=0.02, p=0.730$ and $\beta=0.02, p=0.731$, respectively). These 2 sub-items were only 


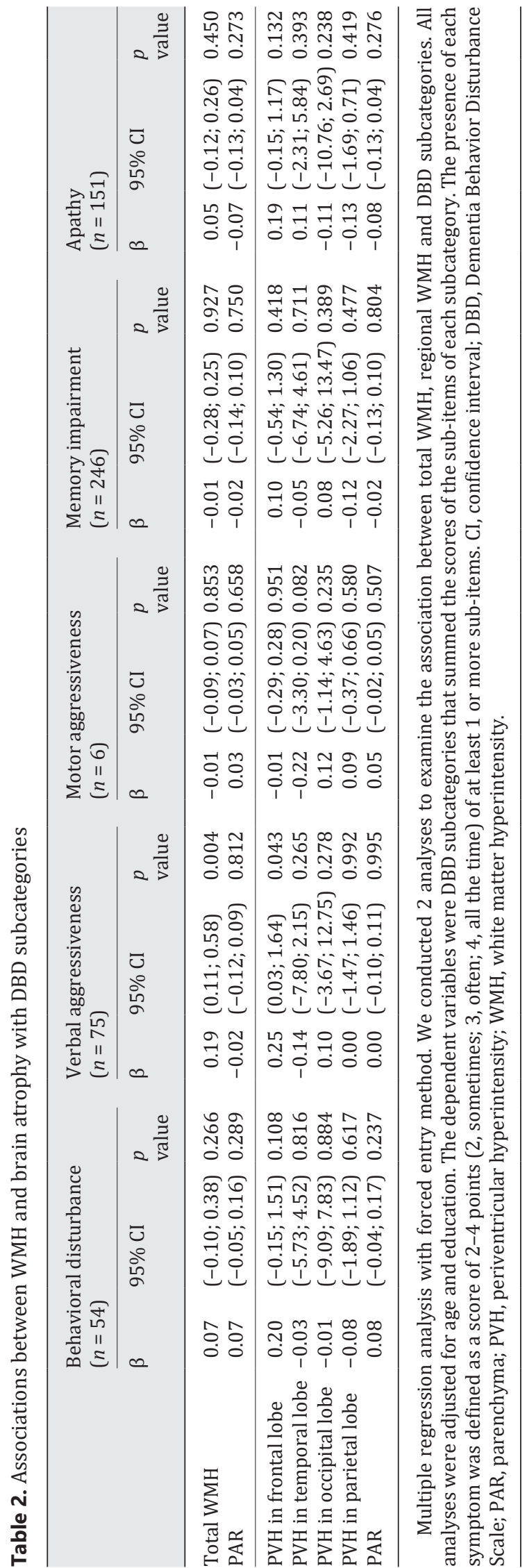


Ogama et al.: Frontal White Matter Hyperintensity Is Associated with Verbal Aggressiveness in Elderly Women with $\mathrm{AD}$ and $\mathrm{aMCl}$

Table 3. Associations between clinical parameters and verbal aggressiveness

\begin{tabular}{|c|c|c|c|}
\hline & \multicolumn{3}{|c|}{ Verbal aggressiveness } \\
\hline & $\beta$ & $95 \% \mathrm{CI}$ & $R^{2}$ \\
\hline Age & 0.03 & $(-0.04 ; 0.07)$ & 0.001 \\
\hline Education & -0.13 & $(-0.30 ;-0.01)$ & 0.017 \\
\hline Mini-Mental State Examination & -0.16 & $(-0.18 ;-0.02)$ & 0.025 \\
\hline \multicolumn{4}{|l|}{ Activity of daily living } \\
\hline Barthel Index & -0.18 & $(-0.19 ;-0.03)$ & 0.031 \\
\hline Lawton Index & -0.27 & $(-0.53 ;-0.20)$ & 0.070 \\
\hline \multicolumn{4}{|l|}{ Mood disturbance } \\
\hline Geriatric Depression Scale & 0.08 & $(-0.04 ; 0.18)$ & 0.006 \\
\hline Vitality Index & -0.19 & $(-0.66 ;-0.14)$ & 0.034 \\
\hline \multicolumn{4}{|l|}{ Geriatric syndromes } \\
\hline Number of geriatric syndromes & 0.22 & $(0.18 ; 0.62)$ & 0.047 \\
\hline Lower urinary tract symptoms & 0.12 & $(-0.03 ; 1.21)$ & 0.014 \\
\hline Pain & 0.07 & $(-0.27 ; 0.92)$ & 0.005 \\
\hline Fatigue & 0.24 & $(0.65 ; 1.93)$ & 0.058 \\
\hline Constipation or diarrhea & 0.11 & $(-0.09 ; 1.29)$ & 0.011 \\
\hline Sleep problems & 0.11 & $(-0.09 ; 1.46)$ & 0.012 \\
\hline \multicolumn{4}{|l|}{ Medication } \\
\hline Polypharmacy & 0.10 & $(-0.10 ; 1.07)$ & 0.010 \\
\hline Donepezil & 0.09 & $(-0.22 ; 1.21)$ & 0.007 \\
\hline Memantine hydrochloride & 0.03 & $(-2.44 ; 4.26)$ & 0.001 \\
\hline Antipsychotics & 0.17 & $(0.37 ; 2.28)$ & 0.029 \\
\hline Anti-anxiety/sleeping medicine & 0.02 & $(-0.57 ; 0.77)$ & 0.000 \\
\hline
\end{tabular}

Single regression analysis. The dependent variables were verbal aggressiveness of the DBD subcategory. $R^{2}$ is the proportion of explained variance of verbal aggressiveness. CI, confidence interval; DBD, Dementia Behavior Disturbance Scale.

associated with fewer years of education $(\beta=-0.18, p=0.009$ for "cries or laughs inappropriately") and number of geriatric syndromes ( $\beta=0.16, p=0.019$ for "screams for no reason").

In model 2, age, education, PVH in the frontal lobe, brain atrophy, classical confounders, and clinical indices showing an association with verbal aggressiveness were entered as independent variables. The results revealed that PVH in the frontal lobe was independently associated with the category of verbal aggressiveness and the sub-items "makes unwarranted accusations" and "verbally abusive, swears." In addition, treatment with antipsychotics was associated with the category of verbal aggressiveness and the 2 sub-items. Fewer years of education and fatigue were associated with the category of verbal aggressiveness and the sub-item "verbally abusive, swears." The number of geriatric syndromes was associated with "makes unwarranted accusations."

\section{Discussion}

The current study revealed that PVH in the frontal lobe was independently associated with verbal aggressiveness in female patients with mild to moderate AD or aMCI. This association remained significant even after multivariable adjustment, including brain atrophy, cognitive impairment, geriatric syndrome, medication, and environmental factors. 
Ogama et al.: Frontal White Matter Hyperintensity Is Associated with Verbal Aggressiveness in Elderly Women with AD and aMCI

Table 4. Independent risk factors for verbal aggressiveness

\begin{tabular}{|c|c|c|c|c|c|c|c|c|c|}
\hline & \multirow{2}{*}{\multicolumn{3}{|c|}{ Verbal aggressiveness }} & \multicolumn{6}{|c|}{ Verbal aggressiveness sub-items } \\
\hline & & & & \multicolumn{3}{|c|}{ makes unwarranted accusations } & \multicolumn{3}{|c|}{ verbally abusive, swears } \\
\hline & $\beta$ & $95 \% \mathrm{CI}$ & $p$ value & $\beta$ & $95 \% \mathrm{CI}$ & $p$ value & $\beta$ & $95 \% \mathrm{CI}$ & $p$ value \\
\hline \multicolumn{10}{|l|}{ Model 1} \\
\hline Age & -0.11 & $(-0.12 ; 0.01)$ & 0.122 & -0.11 & $(-0.05 ; 0.01)$ & 0.113 & -0.08 & $(-0.04 ; 0.01)$ & 0.277 \\
\hline Education & -0.17 & $(-0.35 ;-0.04)$ & 0.012 & -0.12 & $(-0.12 ; 0.01)$ & 0.081 & -0.15 & $(-0.14 ;-0.01)$ & 0.028 \\
\hline $\mathrm{PVH}$ in frontal lobe & 0.17 & $(0.14 ; 1.03)$ & 0.011 & 0.24 & $(0.16 ; 0.54)$ & $<0.001$ & 0.14 & $(0.01 ; 0.39)$ & 0.044 \\
\hline PAR & -0.02 & $(-0.12 ; 0.09)$ & 0.778 & -0.09 & $(-0.08 ; 0.02)$ & 0.197 & -0.01 & $(-0.05 ; 0.04)$ & 0.939 \\
\hline Mini-Mental State Examination & -0.11 & $(-0.15 ; 0.01)$ & 0.094 & -0.12 & $(-0.07 ; 0.00)$ & 0.054 & -0.09 & $(-0.06 ; 0.01)$ & 0.174 \\
\hline Number of geriatric syndromes & 0.24 & $(0.20 ; 0.67)$ & $<0.001$ & 0.24 & $(0.09 ; 0.29)$ & $<0.001$ & 0.20 & $(0.06 ; 0.26)$ & 0.002 \\
\hline Polypharmacy & 0.00 & $(-0.59 ; 0.63)$ & 0.946 & 0.00 & $(-0.27 ; 0.26)$ & 0.955 & 0.05 & $(-0.15 ; 0.37)$ & 0.409 \\
\hline Social activity & -0.07 & $(-0.97 ; 0.27)$ & 0.263 & -0.01 & $(-0.28 ; 0.26)$ & 0.941 & -0.10 & $(-0.48 ; 0.05)$ & 0.110 \\
\hline \multicolumn{10}{|l|}{ Model 2} \\
\hline Age & -0.13 & $(-0.12 ; 0.00)$ & 0.063 & -0.12 & $(-0.05 ; 0.00)$ & 0.079 & -0.10 & $(-0.05 ; 0.01)$ & 0.169 \\
\hline Education & -0.17 & $(-0.34 ;-0.05)$ & 0.009 & -0.12 & $(-0.13 ; 0.00)$ & 0.066 & -0.15 & $(-0.14 ;-0.01)$ & 0.017 \\
\hline $\mathrm{PVH}$ in frontal lobe & 0.14 & $(0.05 ; 0.91)$ & 0.028 & 0.22 & $(0.13 ; 0.51)$ & 0.001 & 0.13 & $(0.00 ; 0.37)$ & 0.048 \\
\hline PAR & -0.01 & $(-0.11 ; 0.10)$ & 0.936 & -0.08 & $(-0.07 ; 0.02)$ & 0.238 & -0.01 & $(-0.05 ; 0.04)$ & 0.873 \\
\hline Mini-Mental State Examination & -0.06 & $(-0.12 ; 0.04)$ & 0.343 & -0.10 & $(-0.06 ; 0.01)$ & 0.154 & & $\mathrm{~N} / \mathrm{A}$ & \\
\hline Number of geriatric syndromes & 0.11 & $(-0.07 ; 0.47)$ & 0.140 & 0.16 & $(0.01 ; 0.24)$ & 0.035 & 0.07 & $(-0.06 ; 0.17)$ & 0.384 \\
\hline Polypharmacy & \multicolumn{3}{|c|}{$\mathrm{N} / \mathrm{A}$} & \multicolumn{3}{|c|}{$\mathrm{N} / \mathrm{A}$} & \multicolumn{3}{|c|}{$\mathrm{N} / \mathrm{A}$} \\
\hline Social activity & \multicolumn{3}{|c|}{$\mathrm{N} / \mathrm{A}$} & \multicolumn{3}{|c|}{$\mathrm{N} / \mathrm{A}$} & \multicolumn{3}{|c|}{$\mathrm{N} / \mathrm{A}$} \\
\hline Lawton Index & -0.12 & $(-0.37 ; 0.03)$ & 0.099 & -0.07 & $(-0.13 ; 0.05)$ & 0.358 & -0.09 & $(-0.14 ; 0.03)$ & 0.224 \\
\hline Vitality Index & -0.08 & $(-0.47 ; 0.10)$ & 0.206 & -0.05 & $(-0.17 ; 0.08)$ & 0.482 & -0.12 & $(-0.23 ; 0.01)$ & 0.080 \\
\hline Fatigue & 0.16 & $(0.08 ; 1.63)$ & 0.031 & 0.08 & $(-0.15 ; 0.53)$ & 0.279 & 0.20 & $(0.11 ; 0.78)$ & 0.009 \\
\hline Antipsychotics & 0.14 & $(0.18 ; 1.99)$ & 0.019 & 0.14 & $(0.08 ; 0.87)$ & 0.020 & 0.13 & $(0.05 ; 0.83)$ & 0.028 \\
\hline
\end{tabular}

Multiple regression analysis with forced entry method. The dependent variables were verbal aggressiveness and sub-items. Model 1: age, education, PVH in the frontal lobe, PAR, and classical confounders (Mini-Mental State Examination, number of geriatric syndromes, polypharmacy, and social activity) were entered as independent variables. Model 2: age, education, $\mathrm{PVH}$ in the frontal lobe, PAR, and classical confounders $(p<0.1$ in model 1$)$ and clinical indices (Lawton Index, Vitality Index, fatigue, and antipsychotics, which exhibited the highest $R^{2}$ values in each clinical section in Table 3 ) were entered as independent variables. N/A indicates that the model was not conducted because classical confounders were $p>0.1$ in model 1 . CI, confidence interval; PAR, parenchyma; PVH, periventricular hyperintensity.

To date, several studies have examined the relationship between whole-brain WMH and BPSD [14-17], but their results were inconsistent. We first demonstrated that PVH in the frontal lobe was significantly associated with verbal aggressiveness. Aggression in dementia has been found to be related to neural networks in various brain regions, particularly in frontal areas $[33,34]$. Several studies have reported that patients with aggression exhibit more atrophy in the frontal cortex and limbic regions, including the cingulate cortex, amygdala, and insula [35-37], and hypoperfusion in the frontotemporal cortex [38]. Furthermore, reduced white matter integrity in the anterior cingulum was significantly associated with irritability and a tendency to exhibit agitation [39]. Frontal regions have abundant connections with major projecting fibers, including the integration of limbic and emotional information into behavioral responses [40]. The participants in the current study exhibited relatively moderate to severe WMH volume $(17.0 \mathrm{~mL}, 1.28 \%$ of IC volume), corresponding to grade 2-3 on the Fazekas scale [32]. In addition, most of the observed WMH was distributed in the periventricular region. Deep subcortical regions connect to adjacent areas via U-fibers, whereas the periventricular region contains long association fibers that connect to distant multiple brain areas. Therefore, the current observations indicated that frontal PVH disrupts neural pathways mainly in the frontal lobe and its associated networks, which may provoke verbal aggressiveness.

In contrast to our observations, several previous studies have reported no significant associations between WMH and aggression [14-16, 18]. Furthermore, one previous study 
reported that aggression was more directly related to AD pathology than vascular lesions [41]. These discrepancies may be related to the heterogeneous methodologies used for the assessment of aggression and differences in the study populations. In the current study, we used the DBD for the assessment of BPSD, whereas most previous studies have used the neuropsychiatric inventory (NPI) [14-16, 18]. The NPI encompasses related subdomains, and the "agitation/aggression" domain includes physical aggression, verbal aggression, and resistance to care $[42,43]$. Thus, even though patients exhibit different types of aggressive behaviors, they are included in the "agitation/aggression" domain. There was no association between WMH and motor aggressiveness in the current study, suggesting that the impact of WMH may vary for different types of aggression. A previous study showed that verbal aggression was significantly associated with lower cerebral blood flow in the left inferior frontal gyrus and the left insula, whereas physical aggression was significantly associated with the right superior temporal gyrus and the right inferior frontal gyrus [44]. Regarding the study population, the current study included only female patients with mild to moderate AD or aMCI. Female AD and aMCI patients have been shown to exhibit verbal aggressiveness more frequently, while male patients tend to exhibit more physical aggressiveness $[19,45]$. Moreover, aggression typically increases with $\mathrm{AD}$ progression [46]. The participants in the current study were early AD and aMCI patients with preserved verbal abilities, possibly resulting in verbal aggressiveness occurring more often than motor aggressiveness. Moreover, the sub-items "cries or laughs inappropriately" and "screams for no reason," which do not require language ability, were not related to frontal PVH in the current study. Thus, frontal PVH may affect verbal aggressiveness during the period in which language ability is maintained. Because aggressiveness is reported to be predictive of rapid progression to severe dementia and earlier death [7], treating aggression in early AD or aMCI may have important benefits.

Previous studies indicated that WMH has a higher prevalence in AD patients, and aMCI patients exhibit an intermediate level of $\mathrm{WMH}$ between that of AD patients and persons with normal cognition [9]. Cerebral amyloid angiopathy (CAA) is often found in AD and is an important contributor to WMH formation [8, 47]. A recent imaging study by the Alzheimer's Disease Neuroimaging Initiative (ADNI) revealed a relationship between periventricular WMH and elevated cerebral amyloid [48]. Interestingly, a regional analysis in that study revealed that periventricular WMH in the frontal lobe was associated with elevated amyloid in subjects with normal cognition, whereas there was no significant association in MCI subjects. CAA is reported to be more predominant in posterior areas [49], and the distribution of WMH in patients with CAA has been predominantly observed in posterior regions $[50,51]$. Conversely, a frontal predominance of WMH has been shown in normal elderly individuals and markedly increases with aging $[52,53]$. Thus, the current results suggest that patients with $\mathrm{AD}$ may have predominantly exhibited posterior $\mathrm{WMH}$, but the further addition of frontal WMH may be related to the specific features of BPSD. There is evidence that aging and hypertension are strong risk factors for WMH progression, but diabetes, dyslipidemia, inflammation, oxidative stress, and sleeping disorders are also associated with the acceleration of WMH [54]. Prevention and therapeutic intervention for these risk factors may be valuable for suppressing the progression of $\mathrm{WMH}$, particularly in frontal regions.

Consistent with previous studies, geriatric syndrome and fatigue were significantly associated with verbal aggressiveness $[20,45,55,56]$. Medical problems in older persons with dementia can cause discomfort and play a critical role in verbal aggressiveness [20, 45, 55]. Fatigue is one of the stressors underlying BPSD [57], and verbal aggressiveness is exacerbated by fatigue [56]. One previous study suggested that verbal aggressiveness can result from discomfort due to daytime fatigue caused by insufficient sleep [58]. In the current study, 
participants with sleep problems exhibited more fatigue than those without sleep problems (50.0 vs. $22.2 \%, p<0.001, \chi^{2}$ test). Thus, comprehensive treatment of geriatric syndromes, particularly fatigue, may reduce verbal aggressiveness in persons with dementia.

Use of antipsychotic medication was significantly associated with verbal aggressiveness. Although treatment with antipsychotics in the management of BPSD is controversial because of the risk of adverse effects, antipsychotics are commonly prescribed as a pharmacological treatment and can be effective for aggression [20]. In the current study, patients who were treated with antipsychotics had high scores for the sub-items "makes unwarranted accusations" (1.2 vs. $0.6, p=0.008$, unpaired $t$ test) and "verbally abusive, swears" (1.1 vs. $0.6, p=0.010$, unpaired $t$ test). Therefore, it is likely that antipsychotic treatment was an associated factor in the current study but may not be a risk factor for verbal aggressiveness.

The current study involved several limitations that should be considered. First, because the study design was cross-sectional, the potential causality between WMH and verbal aggressiveness should be considered cautiously. Second, because the DBD does not include psychotic domains, we could not examine the relationship between WMH and psychotic symptoms. One previous study reported that delusions were associated with frontal WMH [18]. Thus, further studies are required to clarify the precise role of regional WMH in psychotic symptoms. Finally, we were unable to analyze WMH by hemisphere. One previous study reported that verbal aggression was associated with lower regional cerebral blood flow in the left hemisphere, whereas physical aggression was associated with blood flow in the right hemisphere [44]. Future studies will be needed to evaluate WMH by hemisphere and clarify this issue further.

In conclusion, PVH in the frontal lobe was independently associated with verbal aggressiveness in female patients with mild to moderate $\mathrm{AD}$ and aMCI. In addition, geriatric syndromes, particularly fatigue, were also associated with verbal aggressiveness. Additional studies in the future would be valuable to provide further evidence to support the present findings and to develop preventive strategies against WMH progression.

\section{Acknowledgments}

The authors gratefully acknowledge Norio Sugimoto (Innovation Center for Clinical Research, NCGG) for technical support with the statistical analysis. This work was financially supported by the Sasakawa Scientific Research Grant from The Japan Science Society for Noriko Ogama, by the grant from the Research Funding for Longevity Sciences (25-6, 28-15) from the NCGG for Takashi Sakurai and Naoki Saji, and Grants-in-Aid for Scientific Research (No. 26870765) from the Japan Society for the Promotion of Science for Naoki Saji.

\section{Disclosure Statement}

The authors report no conflicts of interest. 


\section{References}

1 Finkel SI, Costa e Silva J, Cohen G, Miller S, Sartorius N: Behavioral and psychological signs and symptoms of dementia: a consensus statement on current knowledge and implications for research and treatment. Int Psychogeriatr 1996;8(suppl 3):497-500.

2 Borsje P, Wetzels RB, Lucassen PL, Pot AM, Koopmans RT: The course of neuropsychiatric symptoms in community-dwelling patients with dementia: a systematic review. Int Psychogeriatr 2015;27:385-405.

-3 Feldman H, Scheltens P, Scarpini E, Hermann N, Mesenbrink P, Mancione L, Tekin S, Lane R, Ferris S: Behavioral symptoms in mild cognitive impairment. Neurology 2004;62:1199-1201.

-4 Hurt C, Bhattacharyya S, Burns A, Camus V, Liperoti R, Marriott A, Nobili F, Robert P, Tsolaki M, Vellas B, Verhey F, Byrne EJ: Patient and caregiver perspectives of quality of life in dementia. An investigation of the relationship to behavioural and psychological symptoms in dementia. Dement Geriatr Cogn Disord 2008;26:138146.

5 Kamiya M, Sakurai T, Ogama N, Maki Y, Toba K: Factors associated with increased caregivers' burden in several cognitive stages of Alzheimer's disease. Geriatr Gerontol Int 2014;14(suppl 2):45-55.

6 Forrester SN, Gallo JJ, Smith GS, Leoutsakos JM: Patterns of neuropsychiatric symptoms in mild cognitive impairment and risk of dementia. Am J Geriatr Psychiatry 2016;24:117-125.

7 Peters ME, Schwartz S, Han D, Rabins PV, Steinberg M, Tschanz JT, Lyketsos CG: Neuropsychiatric symptoms as predictors of progression to severe Alzheimer's dementia and death: the Cache County Dementia Progression Study. Am J Psychiatry 2015;172:460-465.

-8 Tomimoto H: White matter integrity and cognitive dysfunction: radiological and neuropsychological correlations. Geriatr Gerontol Int 2015;15(suppl 1):3-9.

-9 Ogama N, Sakurai T, Nakai T, Niida S, Saji N, Toba K, Umegaki H, Kuzuya M: Impact of frontal white matter hyperintensity on instrumental activities of daily living in elderly women with Alzheimer disease and amnestic mild cognitive impairment. PLoS One 2017;12:e0172484.

10 Sonohara K, Kozaki K, Akishita M, Nagai K, Hasegawa H, Kuzuya M, Yokote K, Toba K: White matter lesions as a feature of cognitive impairment, low vitality and other symptoms of geriatric syndrome in the elderly. Geriatr Gerontol Int 2008;8:93-100.

11 Ogama N, Sakurai T, Shimizu A, Toba K: Regional white matter lesions predict falls in patients with amnestic mild cognitive impairment and Alzheimer's disease. J Am Med Dir Assoc 2014;15:36-41.

-12 Pantoni L, Fierini F, Poggesi A; LADIS Study Group: Impact of cerebral white matter changes on functionality in older adults: an overview of the LADIS Study results and future directions. Geriatr Gerontol Int 2015; 15(suppl 1):10-16.

13 Saji N, Ogama N, Toba K, Sakurai T: White matter hyperintensities and geriatric syndrome: an important role of arterial stiffness. Geriatr Gerontol Int 2015;15(suppl 1):17-25.

14 Hirono N, Kitagaki H, Kazui H, Hashimoto M, Mori E: Impact of white matter changes on clinical manifestation of Alzheimer's disease: a quantitative study. Stroke 2000;31:2182-2188.

15 Staekenborg SS, Gillissen F, Romkes R, Pijnenburg YA, Barkhof F, Scheltens P, van der Flier WM: Behavioural and psychological symptoms are not related to white matter hyperintensities and medial temporal lobe atrophy in Alzheimer's disease. Int J Geriatr Psychiatry 2008;23:387-392.

16 Berlow YA, Wells WM, Ellison JM, Sung YH, Renshaw PF, Harper DG: Neuropsychiatric correlates of white matter hyperintensities in Alzheimer's disease. Int J Geriatr Psychiatry 2010;25:780-788.

17 Kandiah N, Chander R, Zhang A, Yee CC: Cerebral white matter disease is independently associated with BPSD in Alzheimer's disease. J Neurol Sci 2014;337:162-166.

-18 Anor CJ, O’Connor S, Saund A, Tang-Wai DF, Keren R, Tartaglia MC: Neuropsychiatric Symptoms in Alzheimer Disease, Vascular Dementia, and Mixed Dementia. Neurodegener Dis 2017;17:127-134.

19 Lövheim H, Sandman PO, Karlsson S, Gustafson Y: Sex differences in the prevalence of behavioral and psychological symptoms of dementia. Int Psychogeriatr 2009;21:469-475.

20 Kales HC, Gitlin LN, Lyketsos CG: Assessment and management of behavioral and psychological symptoms of dementia. BMJ 2015;350:h369.

21 McKhann GM, Knopman DS, Chertkow H, Hyman BT, Jack CR Jr, Kawas CH, Klunk WE, Koroshetz WJ, Manly JJ, Mayeux R, Mohs RC, Morris JC, Rossor MN, Scheltens P, Carrillo MC, Thies B, Weintraub S, Phelps CH: The diagnosis of dementia due to Alzheimer's disease: recommendations from the National Institute on AgingAlzheimer's Association workgroups on diagnostic guidelines for Alzheimer's disease. Alzheimers Dement 2011;7:263-269.

22 Albert MS, DeKosky ST, Dickson D, Dubois B, Feldman HH, Fox NC, Gamst A, Holtzman DM, Jagust WJ, Petersen RC, Snyder PJ, Carrillo MC, Thies B, Phelps CH: The diagnosis of mild cognitive impairment due to Alzheimer's disease: recommendations from the National Institute on Aging-Alzheimer's Association workgroups on diagnostic guidelines for Alzheimer's disease. Alzheimers Dement 2011;7:270-279.

23 Baumgarten M, Becker R, Gauthier S: Validity and reliability of the Dementia Behavior Disturbance Scale. J Am Geriatr Soc 1990;38:221-226.

24 Ogama N, Yoshida M, Nakai T, Niida S, Toba K, Sakurai T: Frontal white matter hyperintensity predicts lower urinary tract dysfunction in older adults with amnestic mild cognitive impairment and Alzheimer's disease. Geriatr Gerontol Int 2016;16:167-174. 
-25 Folstein MF, Folstein SE, McHugh PR: "Mini-mental state.” A practical method for grading the cognitive state of patients for the clinician. J Psychiatr Res 1975;12:189-198.

26 Mahoney FI, Barthel DW: Functional evaluation: the Barthel index. Md State Med J 1965;14:61-65.

27 Lawton MP, Brody EM: Assessment of older people: self-maintaining and instrumental activities of daily living. Gerontologist 1969;9:179-186.

28 Yesavage JA, Brink TL, Rose TL, Lum O, Huang V, Adey M, Leirer VO: Development and validation of a geriatric depression screening scale: a preliminary report. J Psychiatr Res 1982-1983;17:37-49.

29 Toba K, Nakai R, Akishita M, Iijima S, Nishinaga M, Mizoguchi T, Yamada S, Yumita K, Ouchi Y: Vitality Index as a useful tool to assess elderly with dementia. Geriatr Gerontol Int 2002;2:23-29.

-30 Gnjidic D, Hilmer SN, Blyth FM, Naganathan V, Waite L, Seibel MJ, McLachlan AJ, Cumming RG, Handelsman DJ, Le Couteur DG: Polypharmacy cutoff and outcomes: five or more medicines were used to identify communitydwelling older men at risk of different adverse outcomes. J Clin Epidemiol 2012;65:989-995.

-31 Admiraal-Behloul F, van den Heuvel DM, Olofsen H, van Osch MJ, van der Grond J, van Buchem MA, Reiber JH: Fully automatic segmentation of white matter hyperintensities in MR images of the elderly. Neuroimage 2005; 28:607-617.

-32 Ogama N, Saji N, Niida S, Toba K, Sakurai T: Validation of a simple and reliable visual rating scale of white matter hyperintensity comparable with computer-based volumetric analysis. Geriatr Gerontol Int 2015; 15(suppl 1):83-85.

-33 Rosenberg PB, Nowrangi MA, Lyketsos CG: Neuropsychiatric symptoms in Alzheimer's disease: what might be associated brain circuits? Mol Aspects Med 2015;43-44:25-37.

-34 Nowrangi MA, Lyketsos CG, Rosenberg PB: Principles and management of neuropsychiatric symptoms in Alzheimer's dementia. Alzheimers Res Ther 2015;7:12.

-35 Bruen PD, McGeown WJ, Shanks MF, Venneri A: Neuroanatomical correlates of neuropsychiatric symptoms in Alzheimer's disease. Brain 2008;131(Pt 9):2455-2463.

-36 Trzepacz PT, Yu P, Bhamidipati PK, Willis B, Forrester T, Tabas L, Schwarz AJ, Saykin AJ; Alzheimer's Disease Neuroimaging Initiative: Frontolimbic atrophy is associated with agitation and aggression in mild cognitive impairment and Alzheimer's disease. Alzheimers Dement 2013;9(5 suppl):S95-S104.e1.

-37 Hu X, Meiberth D, Newport B, Jessen F: Anatomical correlates of the neuropsychiatric symptoms in Alzheimer's disease. Curr Alzheimer Res 2015;12:266-277.

-38 Hirono N, Mega MS, Dinov ID, Mishkin F, Cummings JL: Left frontotemporal hypoperfusion is associated with aggression in patients with dementia. Arch Neurol 2000;57:861-866.

-39 Tighe SK, Oishi K, Mori S, Smith GS, Albert M, Lyketsos CG, Mielke MM: Diffusion tensor imaging of neuropsychiatric symptoms in mild cognitive impairment and Alzheimer's dementia. J Neuropsychiatry Clin Neurosci 2012;24:484-488.

40 Bonelli RM, Cummings JL: Frontal-subcortical circuitry and behavior. Dialogues Clin Neurosci 2007;9:141151.

-41 Sennik S, Schweizer TA, Fischer CE, Munoz DG: Risk factors and pathological substrates associated with agitation/aggression in Alzheimer's disease: a preliminary study using NACC data. J Alzheimers Dis 2017;55: 1519-1528.

-42 Cummings JL, Mega M, Gray K, Rosenberg-Thompson S, Carusi DA, Gornbein J: The Neuropsychiatric Inventory: comprehensive assessment of psychopathology in dementia. Neurology 1994;44:2308-2314.

43 Cummings JL: The Neuropsychiatric Inventory: assessing psychopathology in dementia patients. Neurology 1997;48(5 suppl 6):S10-S16.

44 Banno K, Nakaaki S, Sato J, Torii K, Narumoto J, Miyata J, Hirono N, Furukawa TA, Mimura M, Akechi T: Neural basis of three dimensions of agitated behaviors in patients with Alzheimer disease. Neuropsychiatr Dis Treat 2014;10:339-348.

45 Lemay M, Landreville P: Review: verbal agitation in dementia: the role of discomfort. Am J Alzheimers Dis Other Demen 2010;25:193-201.

46 Lopez OL, Becker JT, Sweet RA, Klunk W, Kaufer DI, Saxton J, Habeych M, DeKosky ST: Psychiatric symptoms vary with the severity of dementia in probable Alzheimer's disease. J Neuropsychiatry Clin Neurosci 2003;15: 346-353.

47 Reijmer YD, van Veluw SJ, Greenberg SM: Ischemic brain injury in cerebral amyloid angiopathy. J Cereb Blood Flow Metab 2016;36:40-54.

48 Marnane M, Al-Jawadi O0, Mortazavi S, Pogorzelec KJ, Wang BW, Feldman HH, Hsiung GY; Alzheimer's Disease Neuroimaging Initiative: Periventricular hyperintensities are associated with elevated cerebral amyloid. Neurology 2016;86:535-543.

49 Vinters HV, Gilbert JJ: Cerebral amyloid angiopathy: incidence and complications in the aging brain. II. The distribution of amyloid vascular changes. Stroke 1983;14:924-928.

50 Zhu YC, Chabriat H, Godin O, Dufouil C, Rosand J, Greenberg SM, Smith EE, Tzourio C, Viswanathan A: Distribution of white matter hyperintensity in cerebral hemorrhage and healthy aging. J Neurol 2012;259:530-536.

51 Thanprasertsuk S, Martinez-Ramirez S, Pontes-Neto OM, Ni J, Ayres A, Reed A, Swords K, Gurol ME, Greenberg SM, Viswanathan A: Posterior white matter disease distribution as a predictor of amyloid angiopathy. Neurology 2014;83:794-800. 
-52 de Leeuw FE, de Groot JC, Achten E, Oudkerk M, Ramos LM, Heijboer R, Hofman A, Jolles J, van Gijn J, Breteler MM: Prevalence of cerebral white matter lesions in elderly people: a population based magnetic resonance imaging study. The Rotterdam Scan Study. J Neurol Neurosurg Psychiatry 2001;70:9-14.

53 Honda Y, Noguchi A, Maruyama K, Tamura A, Saito I, Sei K, Soga T, Ushiba K, Hirano T, Sakurai T, Shiokawa Y: Volumetric analyses of cerebral white matter hyperintensity lesions on magnetic resonance imaging in a Japanese population undergoing medical check-up. Geriatr Gerontol Int 2015;15(suppl 1):43-47.

54 Sakurai T, Tomimoto H, Pantoni L: A new horizon of cerebral white matter hyperintensity in geriatric medicine. Geriatr Gerontol Int 2015;15(suppl 1):1-2.

55 Cohen-Mansfield J, Dakheel-Ali M, Marx MS, Thein K, Regier NG: Which unmet needs contribute to behavior problems in persons with advanced dementia? Psychiatry Res 2015;228:59-64.

-56 Sloane PD, Davidson S, Buckwalter K, Lindsey BA, Ayers S, Lenker V, Burgio LD: Management of the patient with disruptive vocalization. Gerontologist 1997;37:675-682.

57 Volicer L, Hurley AC: Management of behavioral symptoms in progressive degenerative dementias. J Gerontol A Biol Sci Med Sci 2003;58:837-845.

58 Cariaga J, Burgio L, Flynn W, Martin D: A controlled study of disruptive vocalizations among geriatric residents in nursing homes. J Am Geriatr Soc 1991;39:501-507. 